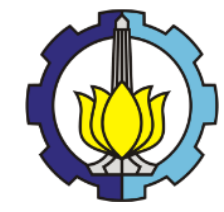

$8^{\text {th }}$ International Conference on

Architecture Research and Design (AR+DC)

November 1-2, 2016

\title{
Sustainable design of past-rural architecture in the present urban- tropical environment
}

\author{
FX Teddy Badai Samodra ${ }^{\mathrm{a}^{*}}$ \\ ${ }^{a}$ Department of Architecture, Institut Teknologi Sepuluh Nopember, Kampus ITS Sukolilo, Surabaya, Indonesia \\ *Corresponding author. Tel.: +6281232508454 \\ E-mail address: fxteddybs@arch.its.ac.id
}

\begin{abstract}
With large open space, traditional houses as representative of rural architecture, have been designed in the past in sufficient air flow. However, nowadays, they fight to accommodate unsupportive environment; high density neighborhoods and global warming effect. This research studies adaptation method and concept of sustainable design of the rural architecture in urban environment of tropical climate. Simultaneous direct measurement and occupant interview were conducted on 19 buildings and 71 respondents. Ecotect Analysis and CFD Fluent program were also used to obtain the proposed model. The results highlighted that by active and passive ventilation method, the occupants respond their urban environment. Moreover, the sustainable design can be reached by raising the floor and roof in order to give higher potency of cooler sufficient air movement through openings and shading. Providing solar chimney as vertical ventilation with sufficient ceiling fan works is also proposed.
\end{abstract}

Keywords: rural architecture; sustainable design; tropical climate; urban environment

\section{Introduction to the subject}

Indonesia has tropical climate, which is represented by the geographical altitude: Lowland and highland. The altitude difference indicates the environment variation (Fig. 1.). As a result, more of the non-physical factors, the traditional building forms are similar for the same social and cultural context. This condition requires adaptation from the occupants in different altitudes. Meanwhile, with large open space, traditional houses as representative of rural architecture, have been designed in the past in sufficient air flow. However, they fight to accommodate unsupportive present urban environment; high density neighborhoods and global warming effect. This study evaluates the building thermal performance for improving tropical building, evaluates the occupant's perception and determines the tropical thermal environment factor and the occupant' adaptation way in a changing environment. Furthermore, it studies adaptation method and concept of sustainable design of the rural architecture in urban environment of tropical climate.

\section{Research theory and methods}

In general, passive control for thermal environment could be distinguished into four basic strategies such as passive solar heating, mass effect, air movement effect, and evaporative cooling (Szokolay, 2008). As for Indonesia, the tropical country, the suitable method could be mass effect, air movement and evaporative cooling. With consideration of high both air temperature and relative humidity in tropical climate and material cost, the ventilation development with accelerating of the air movement is the most possible way. The mass effect is very expensive and the evaporative cooling has risk in raising relative humidity. 


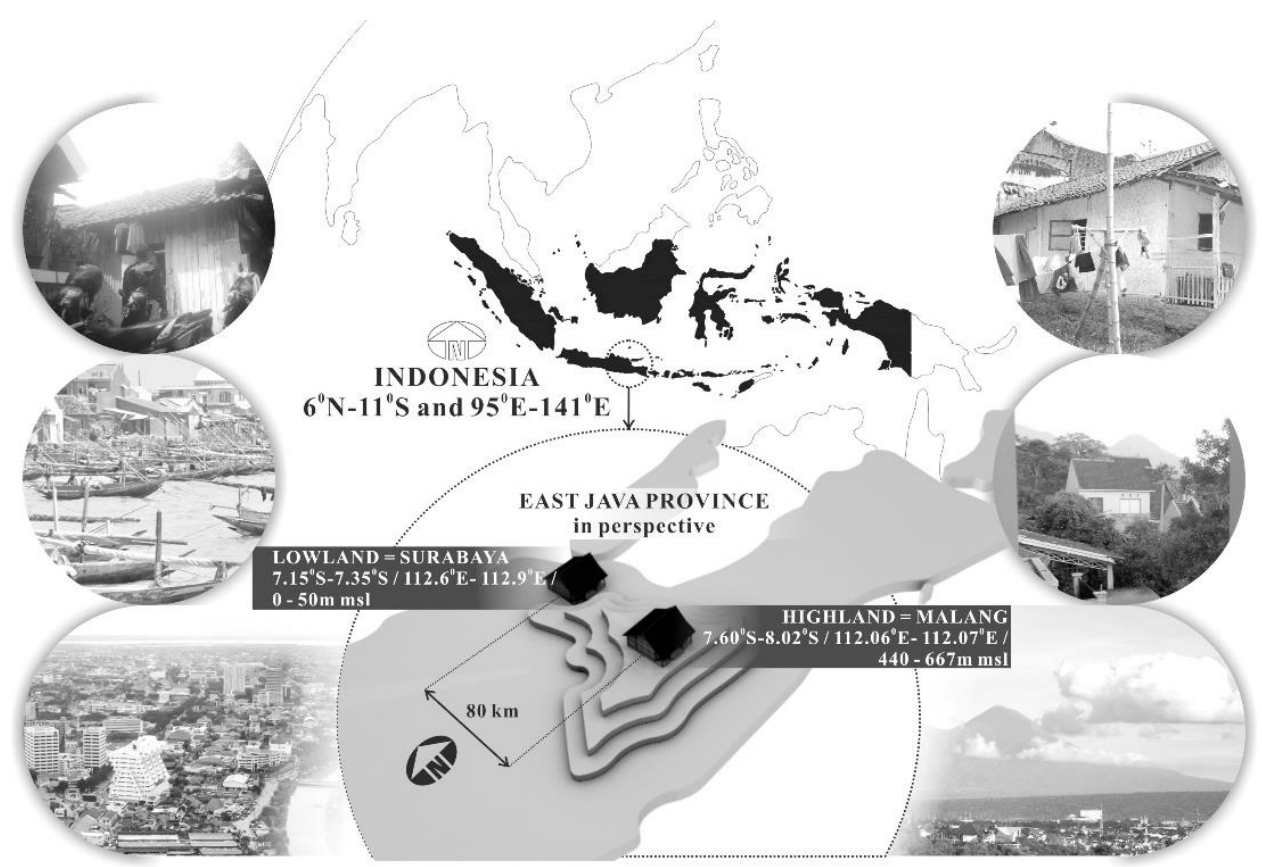

Fig. 1. Research location.

Natural ventilation and direct evaporative cooling have the similar effect (Nguyen \& Reiter, 2014). Natural ventilation is low-cost, easy to apply and provides good indoor air quality, but it relies strongly on natural wind and the building configuration as well as the building location. Indoor thermal comfort could not be reached by a higher air speed only (Prianto \& Depecker, 2003). The integration with other environment factors and building design elements was required. If solar irradiance is more than $700 \mathrm{~W} / \mathrm{m}^{2}$, the significance of the ambient air speed will drop (Tan \& Wong, 2014). Furthermore, under the tropical weather conditions of high solar irradiance and low ambient air speed, cross ventilation performs better than a solar chimney which is recommended under a zero ambient air speed. At high ambient temperatures and high solar intensity in the daytime, the solar chimney can reduce the indoor temperature by $1.0-3.5^{\circ} \mathrm{C}$ compared to the ambient air of $32.0-40.0^{\circ} \mathrm{C}$ (Chungloo \& Limmeechokchai, 2007). In addition, the velocity magnitude can be increased to 4-25\% (Kasaeian, Ghalamchi, \& Ghalamchi, 2014).

The traditional Javanese houses in both lowland (Surabaya) and highland (Malang) regions as a case studies are $6 \times 7 \mathrm{~m}^{2}$ in average size with many variations in materials depending on the location and built period (Fig. 2.). Recently, wood $^{1}$ and/or bamboo ${ }^{2}$ are being used for the walls and the roofs are made from tile ${ }^{3}$ as a building envelope.

The study sets 2 research steps as follows:

(1). Study on traditional building occupants as the main subjects with a thermal vote and direct measurements as a method. The number of remaining traditional buildings were 19 objects, as a representative number in both lowland and highland areas, with 71 occupants (See Table 1.). The range of clothing was 0.16 to 0.57 . The range of metabolic rates was 0.8 to 1.7 , indicating from sleeping to working activities.

(2). Analysis on existing and proposed building simulation of PMV using Ecotect Analysis and ANSYS Fluent (CFD=Computational Fluid Dynamics). Its evaluation consists of natural ventilation, air flow by solar chimney, and PMV. The building plan consists of indoor areas (main room and additional room/service room) and transition area (terrace).

This study proposed the thermal environment improvement with the same housing plan to maintain the occupant indices (clothing and activities/met). The focus of this study was on improving the thermal environment by obtaining thermal comfort in a PMV standard. The main concept is directed at developing ventilation (horizontal and vertical)

\footnotetext{
${ }^{1}$ Thermal properties: $\mathrm{U}$-value $=3.19 \mathrm{~W} / \mathrm{m}^{2} \mathrm{~K}$, Tlag $=0.3$ hour.

${ }^{2}$ Thermal properties: $\mathrm{U}$-value $=3.69 \mathrm{~W} / \mathrm{m}^{2} \mathrm{~K}$, Tlag $=0.1$ hour.

${ }^{3}$ Traditional tile/clay, thermal properties: $\mathrm{U}$-value $=0.84 \mathrm{~W} / \mathrm{m}^{2} \mathrm{~K}$, Tlag $=1.0$ hour.
} 
because by accelerating a sufficient wind speed (V), both the air temperature (T) and relative humidity (RH) are solved simultaneously. Raising the floor and roof are also suggested in order to give higher potency of cooler sufficient air movement through openings and shading. For the Mean Radiant Temperature (MRT), the proposed building provided overhang shadow and surface paint control. Moreover, the occupant indices were also suggested (see Fig. 3. and Fig. 4.).
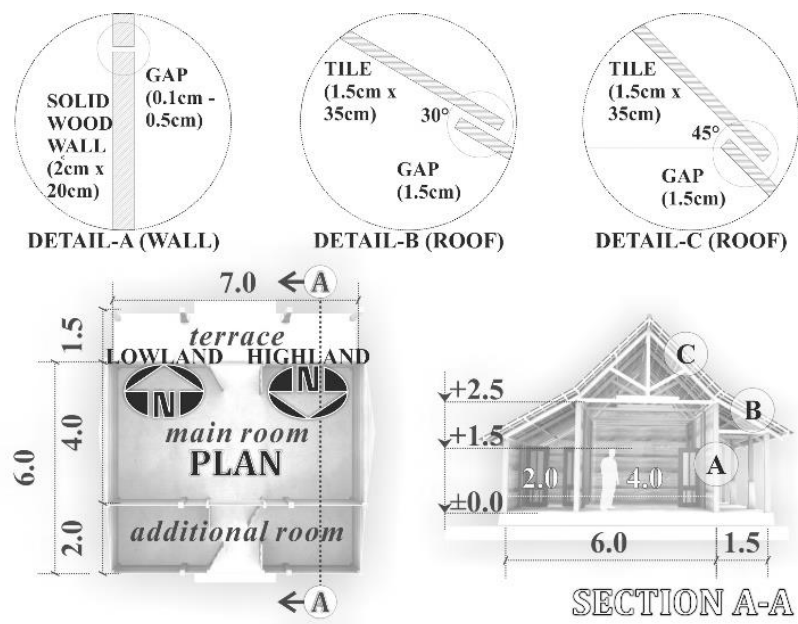

Fig. 2. Building profile.

Table 1. Respondents.

\begin{tabular}{c|l|c|c}
\hline No. & \multicolumn{1}{|c|}{ Information } & Lowland & Highland \\
\hline 1. & Number of Traditional Tropical Houses & 8 & 11 \\
2. & Number of Occupants: & $28:$ & $43:$ \\
& a. Adult Males ( $\geq 17$ years old) & 11 & 13 \\
& b. Adult Females ( $\geq 17$ years old) & 9 & 17 \\
& c. Children $(<17$ years old) & 8 & 13 \\
\hline
\end{tabular}

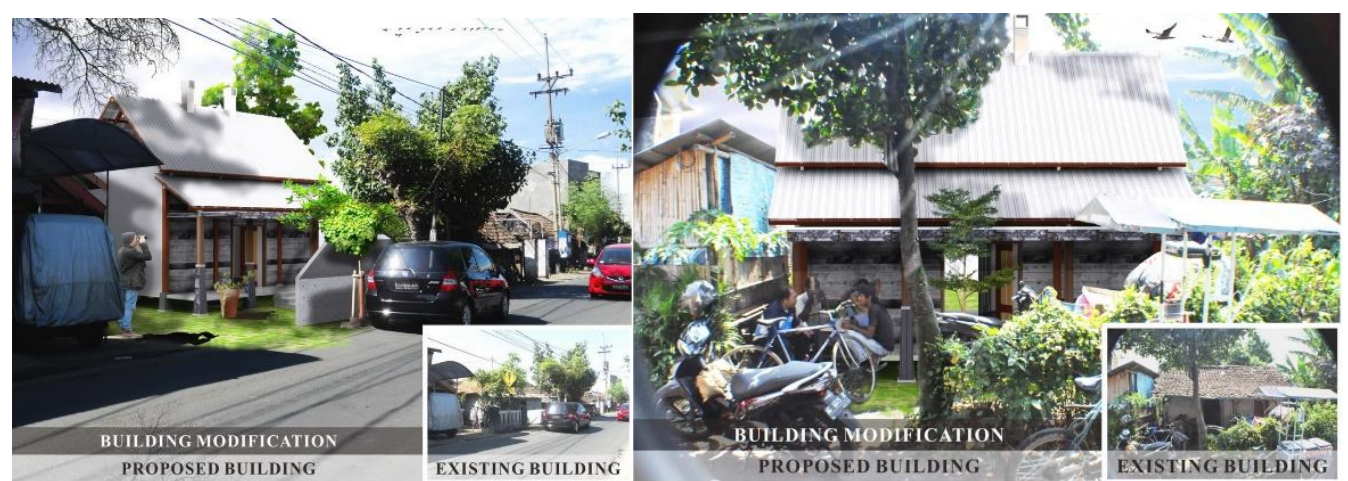

Fig. 3. Modification building of proposed sustainable building. 


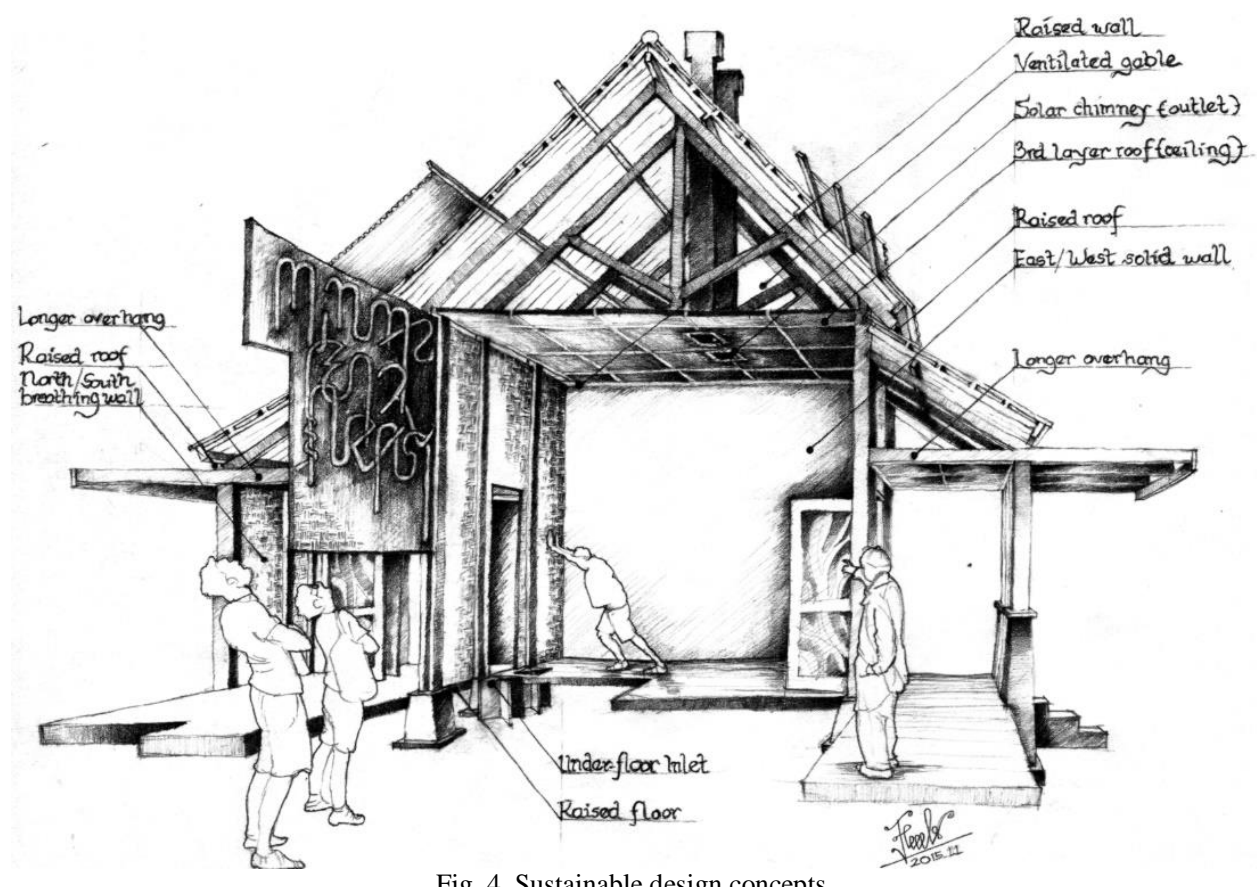

Fig. 4. Sustainable design concepts.

\section{Results and discussion}

\subsection{Factor and method of occupant's adaptation}

In addition to main factor, climate, the changing environment is felt by the occupants (Fig. 5.). Higher building density in the present time is perceived as the largest problem in producing a windy feeling as ventilation makes a contribution. The building dimension also gives a consequence to environmental change in the context of social meaning and population growth. Nevertheless, though the building dimensions are the same, the number of family members is growing, which provide psychological interpretation as a factor of thermal comfort. Physically, the number of members affects the metabolic rate and internal heat gain by occupancy.

(a)

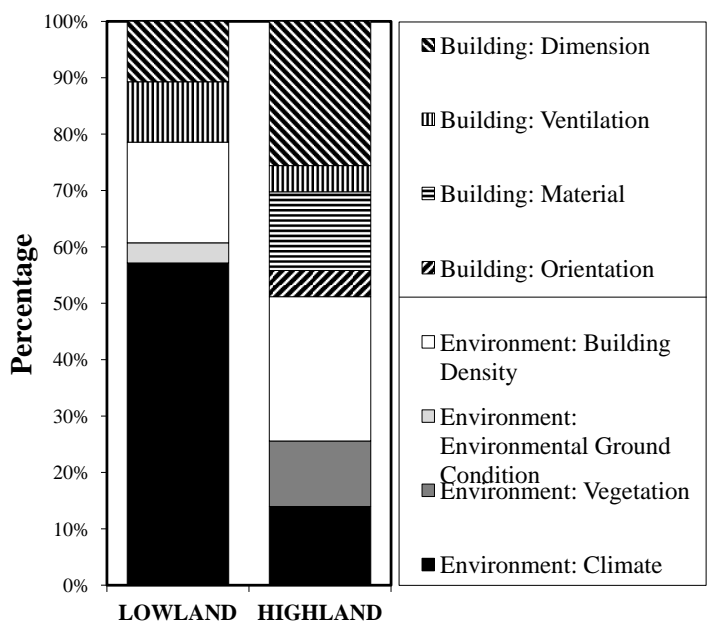

(b)

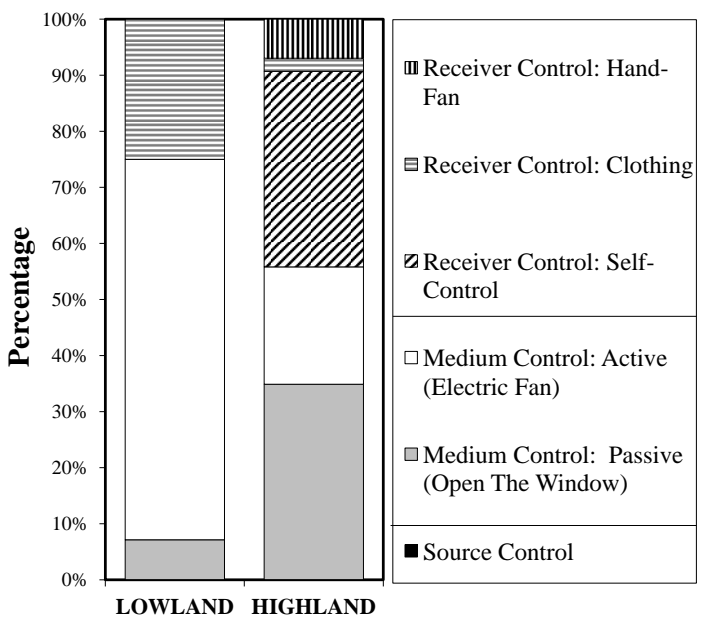

Fig. 5. (a) factor of thermal comfort; (b) thermal adaptation method. 
The natural meaning is perceived as being useless by lowland occupants. A fan, of course, is cheaper than AC (Air Conditioner) and effective for cooling, even though it still uses more energy than natural means. For the occupants (dominated in mid-lower income), this is a critical point. The highland occupants have a distributed method among passive and active in medium control and self-control in the receiver control. The personal adjustment has a relationship with their metabolic rate; if the condition is hot, they tend to do light activities (sleeping/resting). The occupants did not have the will or capability for source interruption. Source means the factors. The occupants made no efforts to change the source. The adaption in using ventilation indicated the use of windows or fans as a function, instead of redesign efforts.

\subsection{Existing condition}

The existing building has a hot environment (PMV is >1), not only for indoors, but also in outdoors, which effects the ground reflectance (Fig. 6.). When the lowland building has environmental problem, the highland building almost reaches the comfort criteria of PMV. Except for harder activity conducted in additional room, the other zones have 0.5 of PMV. Therefore, as analyzed by minimum wind speed, $0.8 \mathrm{~m} / \mathrm{s}$ for physiological cooling, it should be improved by ventilation as proposed building design (Samodra, 2016).

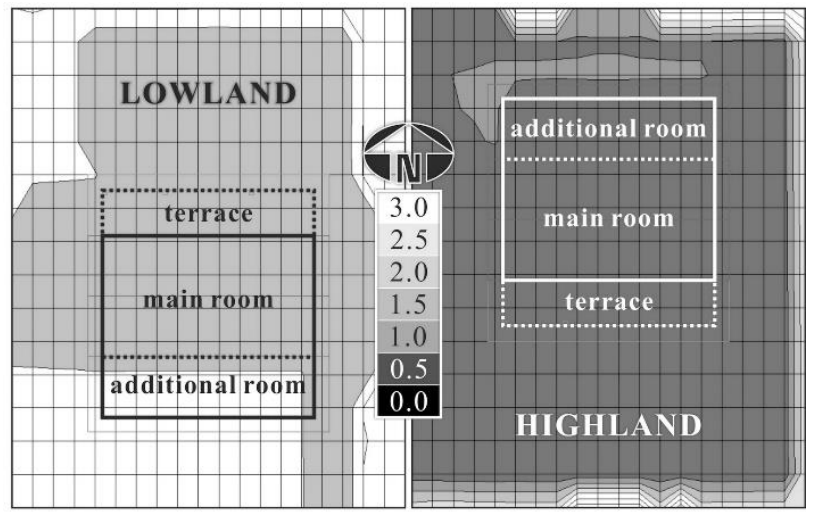

Fig. 6. Comparison of the PMV of existing building plans in the hottest time of lowland and highland.

\subsection{Natural ventilation analysis}

Base on field study data, the buildings have opened doors schedule from 05:00 to 19:00 when the occupants stay at home. It is potency for accelerating wind speed in the daytime. On the other hand, for night-time, from 20:00 to 04:00 they are closed, the potency of heat gain is higher even though the ambient/outdoor temperature is lower. Fig. 7. presents the result of a CFD simulation of proposed lowland building with a South overhang and a door as the inlet (based on dominant wind direction in a year provided by climate data of the Center of Meteorology, Climatology, and Geophysics at Juanda and Perak, Surabaya, 1997-2012 for lowland and Center of Climatology at Karangploso, Malang, Indonesia, 1993-2012 for highland). The climate data also provided the wind speed data for the rural terrain roughness that was converted to an urban context as the study object location by a calculation for every reference height. The velocity inlet of the simulation has a wind speed of $1.4 \mathrm{~m} / \mathrm{s}$ (from that climate data and calculation) and $28^{\circ} \mathrm{C}$ according to an Ecotect Analysis calculation based on the field study environment data. The simulation is set in the critical time (15:00, 15th of October). The outlet is categorized as the pressure outlet in the boundary condition with $32^{\circ} \mathrm{C}$ obtained using the same method as the inlet input. The opened door of highland building results better performance as indicated by sufficient wind speed and lower temperature. With the same method of lowland, lower both wind speed and temperature, $1.2 \mathrm{~m} / \mathrm{s}$ and $24^{\circ} \mathrm{C}$, respectively, the building in highland is still cool for hottest time (1st of January). Air cooling by a longer overhang on all sides accelerates directly through opened doors (can be combined with additional windows). Under-floor ventilation reduces both the air temperature and humidity. In fact, 
there is a lower wind speed in the upper part of the room $(<0.4 \mathrm{~m} / \mathrm{s})$, but the lower air temperature is still distributed evenly $\left(27-29^{\circ} \mathrm{C}\right.$ for lowland). This is in comfort zone $\left(24.3-29.3^{\circ} \mathrm{C}\right.$ in average) based on the Psychrometric chart analysis (Samodra, 2016). A small problem is only found in underheated condition of highland building (the lower part of highland building gets $23-25^{\circ} \mathrm{C}$ ). However, the lower degree-hours potentially and easily could be solved by occupancy (opening schedule and occupant adaptation). Furthermore, the more important problem is when the building opening (aperture) as horizontal ventilation is closed because of occupancy schedule and limitation space of outdoor urban environment. Thus, the vertical ventilation improvement should be implemented.

(a)
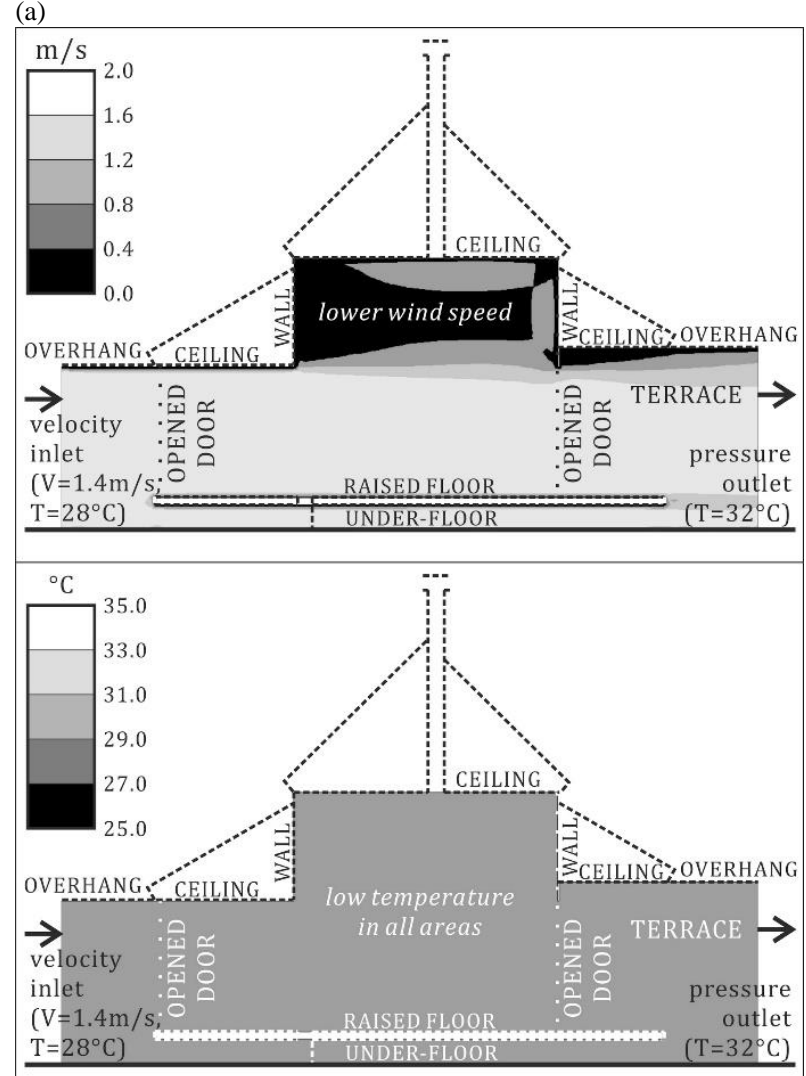

(b)
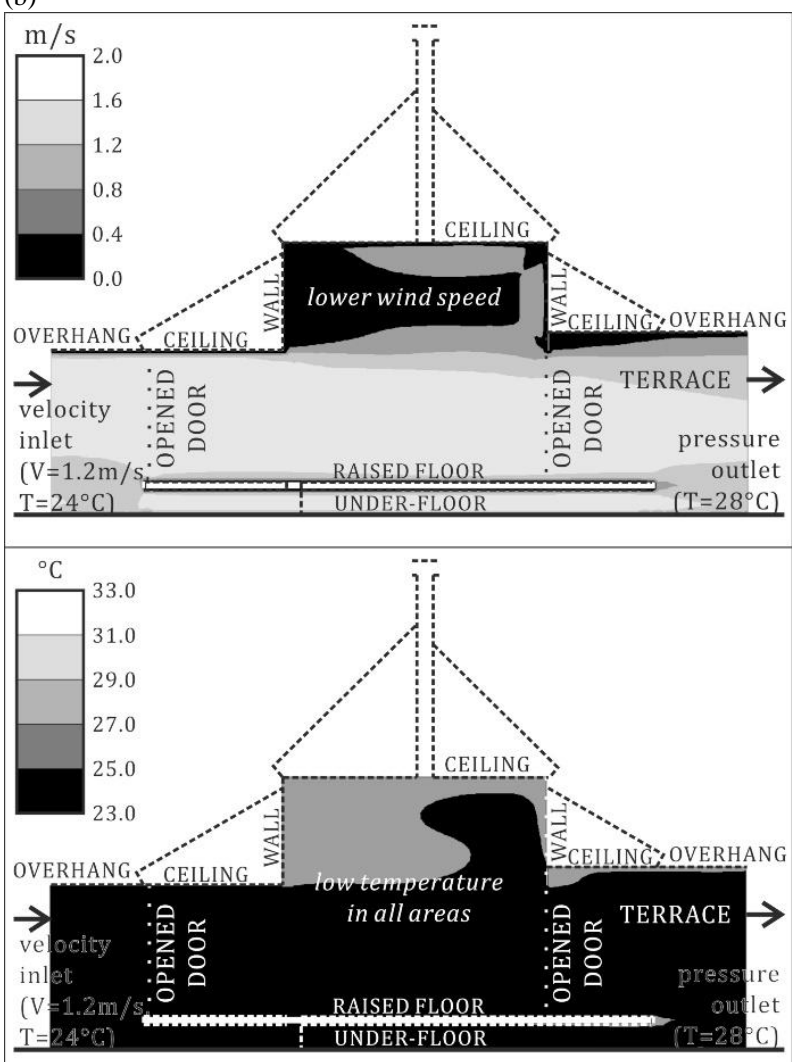

Fig. 7. (a) natural ventilation in the opened door case of the proposed building in lowland; (b) natural ventilation in the opened door case of the proposed building in highland.

Air is cooled by under-floor ventilation (could be combined with water evaporative cooling) and sucked by the pressure and air temperature difference with a solar chimney that is heated by the heat absorber material. For a cooler and more even distribution, it is supported by wall opening ventilation in the upper wall that is cooled by roof shading. The wall opening is useful for controlling the roof heat transfer after being reduced by the attic and ceiling.

With the same inlet and outlet settings as the opened door case, the additional condition of the chimney in lowland building has a surface and air temperature of $50^{\circ} \mathrm{C}$ and $40^{\circ} \mathrm{C}$, respectively. All of them were also the result of an Ecotect Analysis calculation (Fig. 8.). The stack effect is found in the chimney, as indicated by its higher wind speed than the indoor rooms. With a lower reference height, the inlet of the under floor has a lower wind speed, $0.9 \mathrm{~m} / \mathrm{s}$, even though it has the same air temperature input. Furthermore, it potentially has a lower air temperature with its under-floor shading and can be developed more with water evaporative cooling (this study focused on shading, more than evaporative cooling for reducing the air temperature of the inlet). Meanwhile, with about $4^{\circ} \mathrm{C}$ lower air temperature of chimney, the highland building has similar pattern of air movement and wind speed but it has lower indoor temperature, especially for high pressure, supplied area, by higher wind speed. This condition is much better 
than opened door where its underheated is reduced. The natural method is effective for highland when the lowland building still has problem.
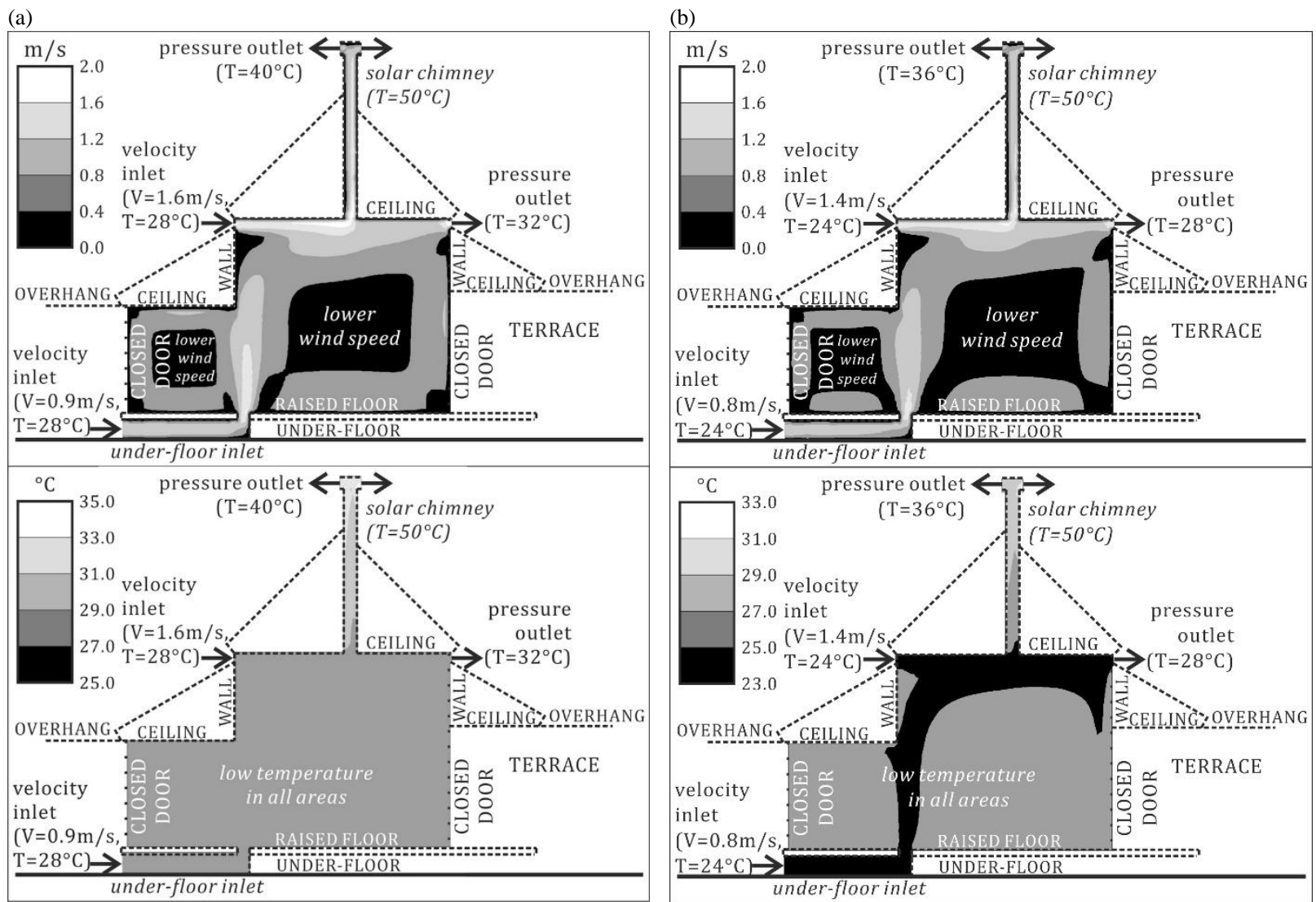

Fig. 8. (a) natural ventilation in the closed door case in lowland; (b) natural ventilation in the closed door case in highland.

(a)

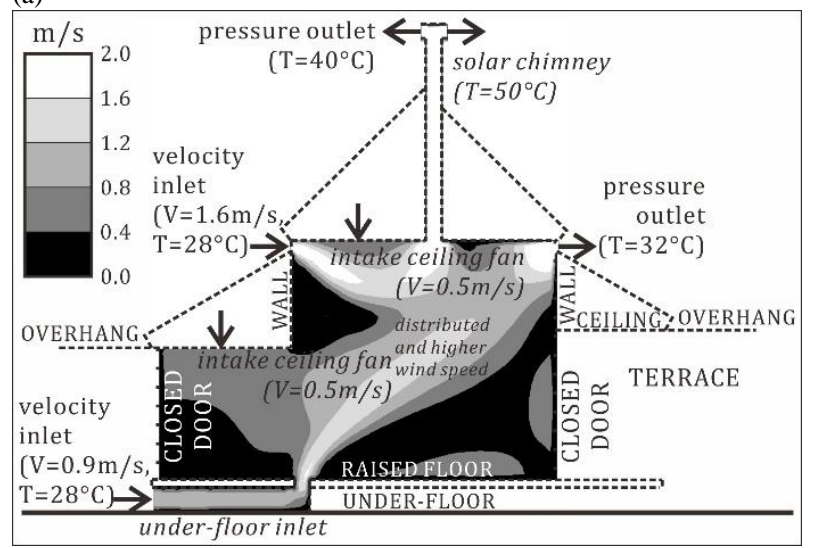

(b)

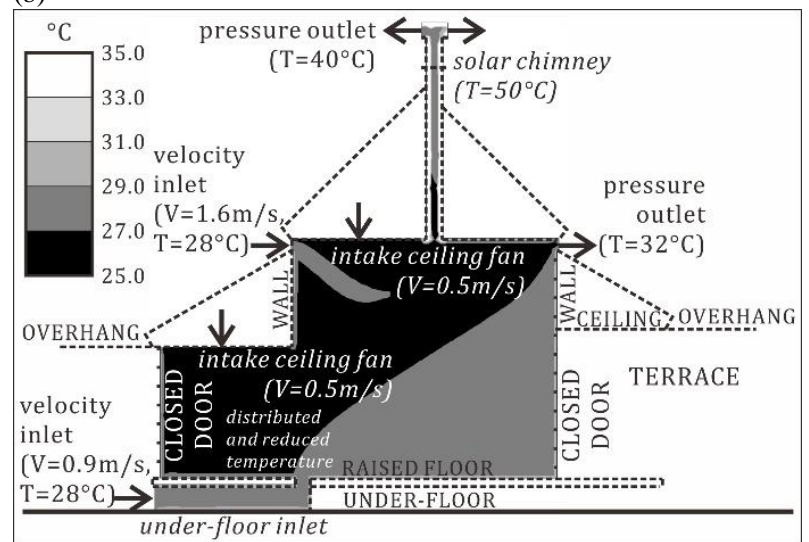

Fig. 9. (a) wind speed in mixed-mode ventilation in the closed door case in lowland.; (b) air temperature in mixed-mode ventilation in the closed door case in lowland. 
In lowland building, by natural method of vertical ventilation, there is a lower wind speed in the center of the room $(<0.4 \mathrm{~m} / \mathrm{s})$, but it has a better air temperature (lower and distributed evenly for indoor) in the comfort range, $24.3-29.3^{\circ} \mathrm{C}$, as in the open door case. This can be solved by mixed-mode/hybrid ventilation with a fan. As recommended by lowland adaptation method (see Fig. 5), the wind speed can be distributed by making a distributed diffuser (inlet) at under-floor. On the other hand, it has the risk of a lower wind speed and many inlets that could cause interior space reduction and interference with the occupant activities.

Fig. 9. shows the additional inlet element with the intake ceiling fans on the main and additional rooms. The wind speed was set to a pleasant condition $(0.5 \mathrm{~m} / \mathrm{s})$ because a lower or higher wind speed not only makes the conditions unpleasant, but it also makes sufficient wind speed for undistributed physiological cooling in the indoor environment. The intake fan is useful not only for providing a higher and more distributed wind speed of indoor areas, but also for reducing the air temperature by approximately $2^{\circ} \mathrm{C}$ than that using natural ventilation only (for the higher activities zone-additional room and half of the main room). Reducing the air temperature with a fan may consume more energy, but it is potential in reducing the cooling load with zero overheating.

\subsection{Air flow analysis on solar chimney}

Based on the flow rate (CFM total) minimum requirement, $51.1 \mathrm{CFM}$ or $0.024 \mathrm{~m}^{3} / \mathrm{s}$ (Samodra, 2016), this proposed study $(\mathrm{d}=0.25 \mathrm{~m})$ should receive minimum a solar intensity of $700 \mathrm{~W} / \mathrm{m}^{2}, 350 \mathrm{~W} / \mathrm{m}^{2}, 400 \mathrm{~W} / \mathrm{m}^{2}$, and 450 $\mathrm{W} / \mathrm{m}^{2}$, for $0.15 \mathrm{~m}, 1.0 \mathrm{~m}, 2.0 \mathrm{~m}$, and $3.0 \mathrm{~m}$ (top of chimney), respectively (Fig. 10.). It shows that located the glass for example for receiving solar radiation in $1 \mathrm{~m}$ is the most efficient. If it is compared to $\mathrm{d}=0.15 \mathrm{~m}$ and $0.35 \mathrm{~m}$, wider chimney shows the higher requirement of solar intensity for resulting higher and sufficient flow rate.
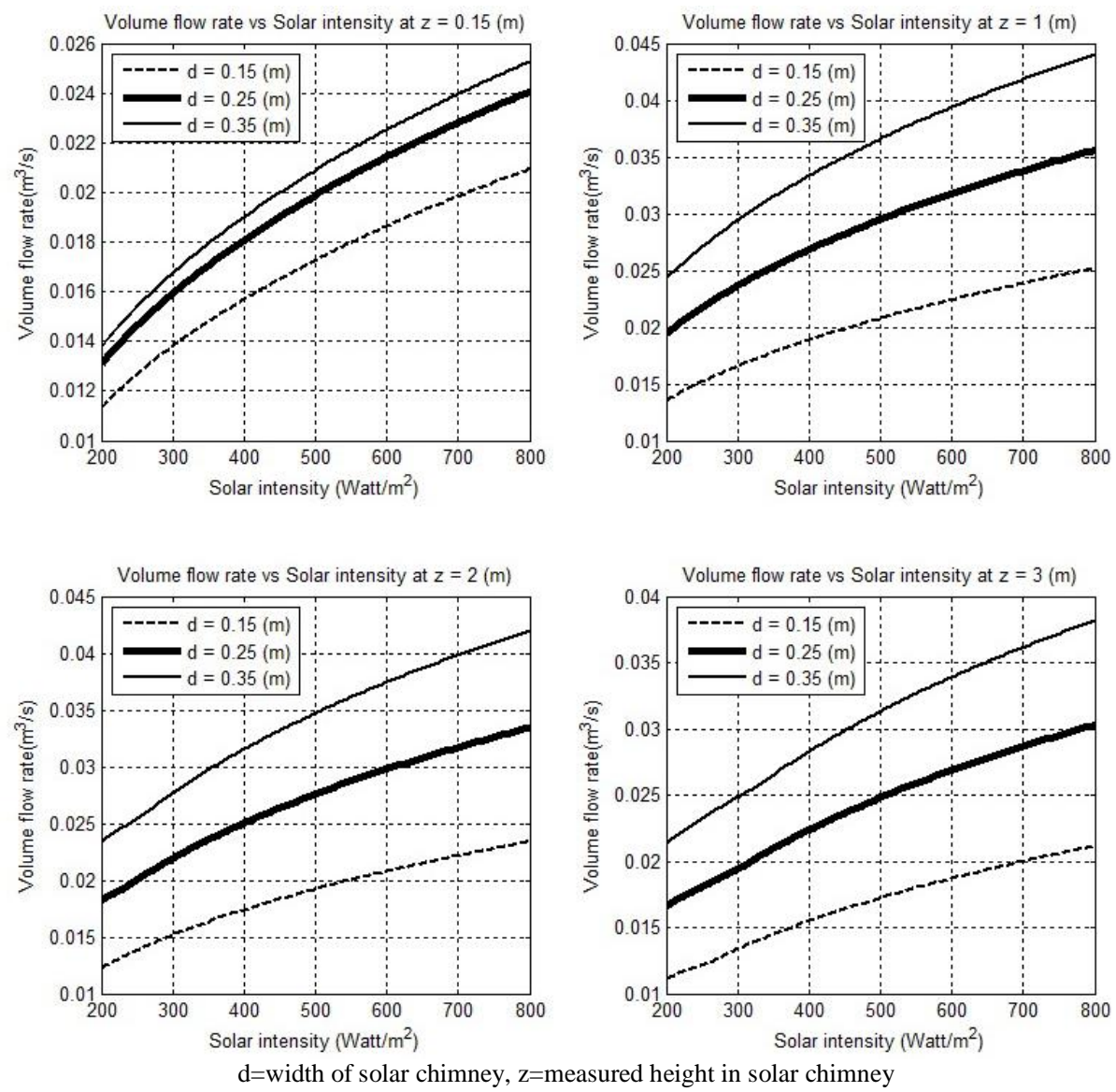

Fig. 10. Flow rate of the solar chimney. 


\subsection{PMV analysis}

With the same materials, the proposed building reaches the PMV standard for indoor, transition and outdoor areas in both using the natural (lowland and highland buildings) and mixed-mode method of ventilation for lowland only (Fig. 11.). Furthermore, shading plays an important role in reducing 0.5 of the PMV in the outdoor and transition areas. Both natural and mixed-mode ventilation result in a PMV in the comfort range $(-5$ to +5$)$ in all zones. On the other hand, there are heavier activities in the additional room, the proposed building maintains the thermal comfort condition (PMV is 0.0-0.5). Meanwhile, the mixed-mode helps to reach the neutral PMV for the indoor zones (main and additional rooms) and half of terrace.

(a)

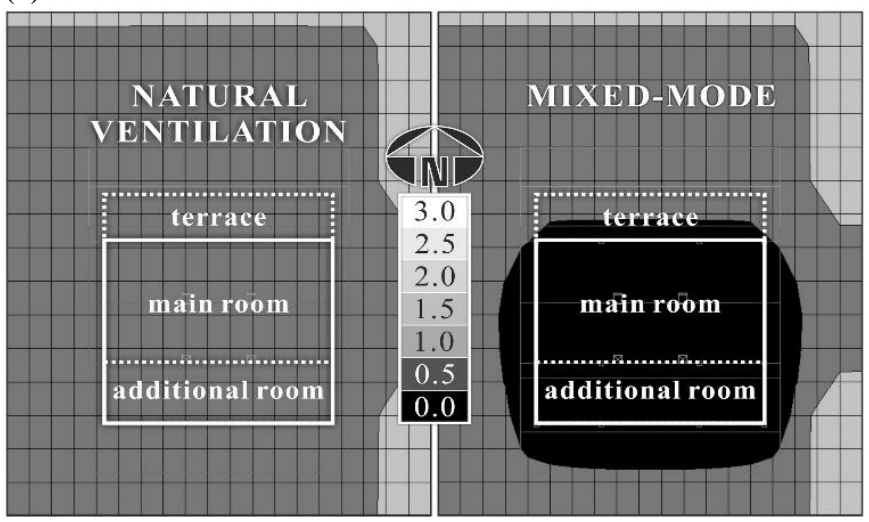

$(15: 00,15$ th of October $)$ (b)

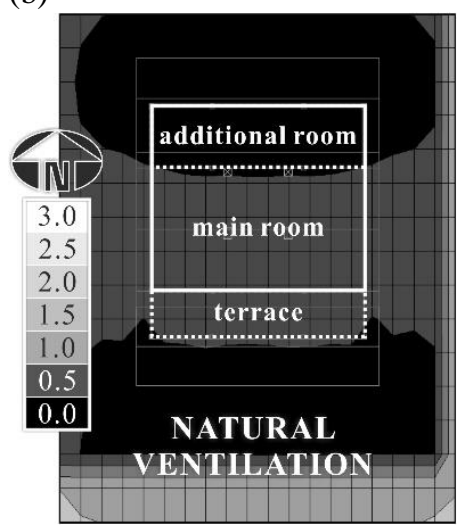

(15:00, 1st of January)

Fig. 11. (a) PMV of the proposed plan in the hottest time of lowland; (b) PMV of the proposed building in the hottest time of highland.

\section{Conclusions}

Climatic determinism fails to differ house forms, but it is important aspect. The changing environment directs the tropical building occupants to vote climate as the most decisive factor that affects their thermal condition. Furthermore, the higher building density in urban environment as additional factor to the building dimension factor in the present time than the past is perceived as the greatest problem in giving a windy feeling. Although the condition is hot in a lowland environment, fans are effective for cooling.

For proposal on thermal environment improvement, both lowland and highland buildings need optimization to reduce cooling load and PMV improvement for existing condition. The ventilation design, horizontal in opened door case and vertical (solar chimney) in closed door case and limited outdoor space should be conducted, because the natural method is not enough for distributing wind speed in lowland. Therefore, the application of fan is effective and the PMV approaches not only still reaching -0.5 to +0.5 as comfort limits, but also it approaches to neutral $(0)$. In terms of occupancy, this study suggests that for better conditions in reducing the cooling load and energy consumption, the occupants should maintain their habit of wearing simple clothing (such as shorts and t-shirts: less than 0.4 clo) and avoid strenuous/heavy activity because it can result high internal heat gain. 


\section{Appendix: Matlab Code}

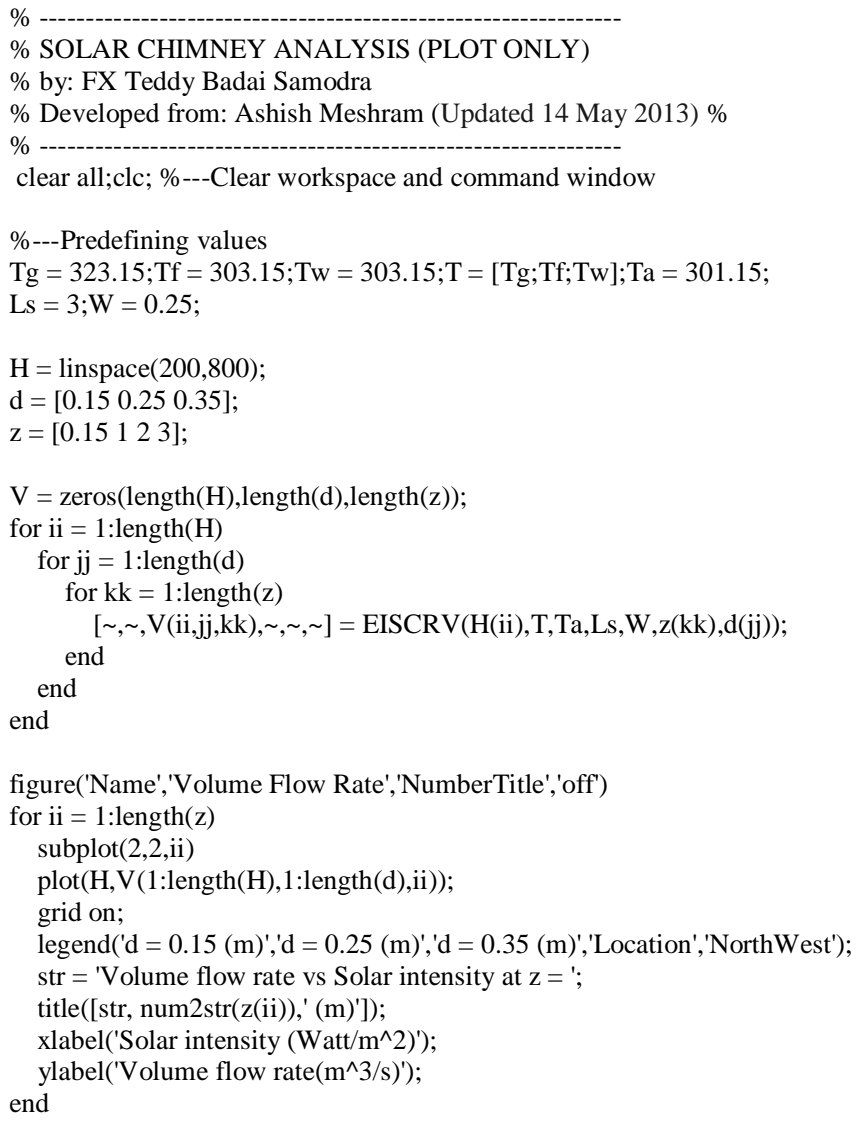

\section{Acknowledgment}

This study was supported by the Directorate General of Resources for Science, Technology and Higher Education (DG-RSTHE), Ministry of Research, Technology, and Higher Education, Republic of Indonesia. The authors gratefully acknowledge the financial and technical support.

\section{References}

Chungloo, S., \& Limmeechokchai, B. (2007). Application of passive cooling systems in the hot and humid climate: The case study of solar chimney and wetted roof in Thailand. Building and Environment, 42(9), 3341-3351. https://doi.org/10.1016/j.buildenv.2006.08.030

Kasaeian, A., Ghalamchi, M., \& Ghalamchi, M. (2014). Simulation and optimization of geometric parameters of a solar chimney in Tehran. Energy Conversion and Management, 83, 28-34. https://doi.org/10.1016/j.enconman.2014.03.042

Nguyen, A.-T., \& Reiter, S. (2014). A climate analysis tool for passive heating and cooling strategies in hot humid climate based on Typical Meteorological Year data sets. Energy and Buildings, 68, 756-763. https://doi.org/10.1016/j.enbuild.2012.08.050

Prianto, E., \& Depecker, P. (2003). Optimization of architectural design elements in tropical humid region with thermal comfort approach. Energy and Buildings, 35(3), 273-280. https://doi.org/10.1016/S0378-7788(02)00089-0

Samodra, F. T. B. (2016). Proposal for Thermal and Noise Environment Improvement of The Traditional House in Indonesia. Pusan National University.

Szokolay, S. V. (2008). Introduction to architectural science : the basis of sustainable design. Oxford: Elsevier/Architectural Press.

Tan, A. Y. K., \& Wong, N. H. (2014). Influences of ambient air speed and internal heat load on the performance of solar chimney in the tropics. 
Solar Energy, 102, 116-125. https://doi.org/10.1016/j.solener.2014.01.023 